\title{
AUDIT ENERGI PADA GELANGGANG MAHASISWA USU MENGGUNAKAN SIMULASI ENERGYPLUS
}

\author{
Immanuel Manurung $^{1 *}$, Terang U.H.S.G Manik ${ }^{2}$, Dian M. Nasuton ${ }^{3}$, Andianto Pintoro ${ }^{4}$ \\ ${ }^{1,2,3,4}$ Departemen Teknik Mesin, Fakultas Teknik, Universitas Sumatera Utara \\ Email: immanuel301@gmail.com
}

\begin{abstract}
Buildings contribute more than a third of annual greenhouse gas emissions and consume more than $40 \%$ of the world's energy consumption. This happens in both developed and developing countries. To overcome the waste of energy use, energy efficiency must be done, one of which is the energy audit method. The purpose of the energy audit is to look for the amount of energy consumption and the intensity of energy consumption (IKE) so that it can determine the steps to obtain energy saving opportunities (PHE). Building energy audits using simulation software such as EnergyPlus is one way to find out how building energy is consumed and find alternatives to reduce energy consumption. The simulation results in the USU Student Center Main Room using EnergyPlus obtained a electrical energy consumption of $7760.3 \mathrm{kWh} /$ month and IKE of $6.51 \mathrm{kWh} / \mathrm{m}^{2} /$ month. The biggest use of energy is in the air system (HVAC), then the energy saving opportunity scenario (PHE) is by replacing the unitary system or Split Air Conditioning (AC) into a Variable Air Volume (VAV) system. After simulation with the VAV system, the results of electricity consumption of $4573.57 \mathrm{kWh} /$ month and IKE are $3.84 \mathrm{kWh} /$ $\mathrm{m}^{2} /$ month. So replacing the HVAC system from unitary System into a VAV system can save energy by $41 \%$.
\end{abstract}

Keywords: Energy Efficiency, Energy Audit, energy consumption, intensity of energy consumption (IKE), energy saving opportunities (PHE), EnergyPlus, Split Air Conditioning, Variable Air Volume (VAV) System.

\begin{abstract}
Abstrak
Bangunan berkontribusi lebih dari sepertiga emisi gas rumah kaca pertahunnya dan mengkonsumsi energi lebih dari $40 \%$ dari konsumsi energi dunia. Hal ini terjadi baik di negara maju maupun negara berkembang. Untuk menanggulangi pemborosan pemakaian energi maka harus dilakukan efisiensi energi, salah satunya dengan metode audit energi. Tujuan dari audit energi adalah untuk mencari besarnya konsumsi energi dan intensitas konsumsi energi (IKE) sehingga dapat menentukan langkah-langkah untuk mendapatkan peluang hemat energi (PHE). Audit energi bangunan dengan menggunakan simulasi perangkat lunak seperti EnergyPlus adalah salah satu cara untuk mengetahui bagaimana konsumsi energi bangunan dan mencari alternatif untuk mengurangi konsumsi energi. Hasil simulasi pada Ruangan Utama Gelanggang Mahasiswa USU menggunakan EnergyPlus didapatkan beban pendingin konsumsi energi listrik $7760.3 \mathrm{kWh} /$ bulan dan IKE sebesar $6.51 \mathrm{kWh} / \mathrm{m}^{2} /$ bulan. Penggunaan energi terbesar terdapat pada sistem tata udara (HVAC), maka skenario peluang hemat energi (PHE) yaitu dengan mengganti sistem unitari atau AC split menjadi sistem Variable Air Volume (VAV). Setelah dilakukan simulasi dengan sistem VAV maka didapatkan hasil konsumsi energi listrik $4573.57 \mathrm{kWh} /$ bulan dan IKE sebesar 3.84 $\mathrm{kWh} / \mathrm{m}^{2} /$ bulan. Maka dengan mengganti sistem HVAC dari sistem unitari menjadi Sistem VAV dapat menghemat energi sebesar $41 \%$.
\end{abstract}

Kata kunci: Efisiensi Energi, Audit Energi, Konsumsi Energi, Intensitas Konsumsi Energi (IKE), Peluang Hemat Energi (PHE), EnergyPlus, AC Split, Sistem Variable Air Volume (VAV). 


\section{PENDAHULUAN}

Bangunan berkontribusi lebih dari sepertiga emisi gas rumah kaca pertahunnya dan mengkonsumsi energi lebih dari 40\% dari konsumsi energi dunia. Hal ini terjadi baik di negara maju maupun negara berkembang ${ }^{[1]}$. Untuk menanggulangi pemborosan pemakaian energi maka harus dilakukan efisiensi energi. Salah satu metode yang sekarang dipakai untuk mengefisienkan pemakaian energi adalah konservasi energi. Konservasi energi adalah upaya mengefisienkan pemakaian energi untuk suatu kebutuhan agar pemborosan energi dapat dihindarkan. Dalam proses ini meliputi adanya audit energi yaitu suatu metode untuk menghitung tingkat konsumsi energi suatu gedung atau bangunan, yang mana hasilnya nanti akan dibandingkan dengan standar yang ada untuk kemudian dicari solusi penghematan konsumsi energi jika tingkat konsumsi energinya melebihi standar baku yang ada ${ }^{[2]}$.

Audit energi bangunan dengan menggunakan simulasi perangkat lunak adalah salah satu cara untuk mengetahui bagaimana konsumsi energi bangunan dan mencari alternatif untuk mengurangi konsumsi energi dan pemborosan energi. Salah satu perangkat lunak yang dapat melakukan simulasi energi bangunan adalah EnergyPlus. Perangkat lunak simulasi energi akan memberikan data berupa beban pendinginan dan profil konsumsi energi dalam jangka waktu tertentu sekaligus memberikan perincian berdasarkan peralatan, seperti sistem tata udara, sistem tata cahaya dan peralatan listrik. Penggunaan simulasi juga dapat memberikan data pada kondisi maksimal ataupun minimal. Adanya data keadaan termal dan data konsumsi energi juga akan memudahkan identifikasi peluang-peluang penghematan energi.

Tujuan dari penelitian ini adalah untuk menentukan konsumsi energi, intensitas konsumsi energi (IKE) dan Peluang Hemat Energi (PHE) dari ruang utama Gedung Gelanggang Mahasiswa USU menggunakan simulasi EnergyPlus.

\section{TEORI DASAR}

\subsection{Konsep Dasar}

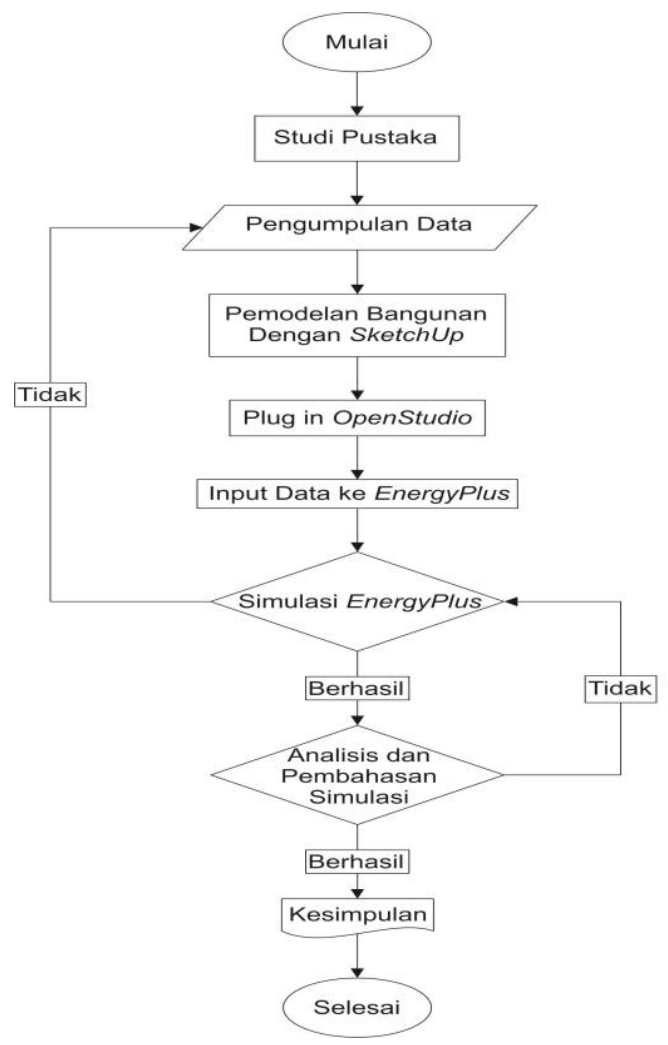




\subsection{Audit Energi}

Beberapa pengertian yang perlu dicatat terkait audit energi menurut SNI 03-6196-2000 adalah ${ }^{[2]}$ :

- Konsumsi energi adalah besarnya energi yang digunakan oleh bangunan gedung dalam periode waktu tertentu dan merupakan perkalian daya dan waktu operasi $(\mathrm{kWh})$.

- Intensitas Konsumsi Energi (IKE) merupakan pembagian antara konsumsi energi dengan satuan luas bangunan gedung $\left(\mathrm{kWh} / \mathrm{m}^{2}\right)$.

- Peluang Hemat Energi (PHE) (Energy Conservation Opportunity/ECO) adalah cara yang mungkin bisa diperoleh dalam usaha mengurangi pemborosan energi. - besarnya peluang penghematan energi .

\subsection{Metode Kesetimbangan Panas}

Metode kesetimbangan panas adalah metode perhitungan beban panas sensibel yang mengaplikasikan hukum pertama termodinamika yaitu hukum kekekalan energi dan prinsipprinsip aljabar matriks ${ }^{[3]}$. Hal yang paling mendasar dari metode kesetimbangan panas adalah udara dalam zona termal dimodelkan tercampur merata (well-stirred) yang artinya udara dalam zona tersebut memiliki keseragaman temperatur.

Perhitungan beban panas sensibel ruangan dengan metode kesetimbangan panas terdiri dari empat unsur yaitu:

1. Kesetimbangan panas sisi luar (outside-face heat balance)

2. Proses konduksi panas pada dinding

3. Kesetimbangan panas sisi dalam (inside-face heat balance)

4. Kesetimbangan panas udara di dalam zona

\subsection{Kesetimbangan Panas Sisi Luar}

Kesetimbangan panas sisi luar dapat dirumuskan secara matematis dengan persamaan [3]:

$$
q^{\prime \prime}{ }_{\text {asol }}+q^{\prime \prime}{ }_{L W R}+q^{\prime \prime}{ }_{\text {conv }}+q{ }_{k o}=0
$$

Dimana :

$q{ }^{\prime \prime}{ }_{\text {asol }}=$ fluks radiasi matahari langsung dan difusi yang diserap (q/A) $\left(\mathrm{W} / \mathrm{m}^{2}\right)$,

$q^{\prime \prime}{ }_{L W R}=$ pertukaran netto fluks radiasi gelombang panjang dengan udara dan lingkungan sekitar $\left(\mathrm{W} / \mathrm{m}^{2}\right)$,

$q^{\prime \prime}{ }_{\text {conv }}=$ fluks pertukaran konveksi dengan udara luar $\left(\mathrm{W} / \mathrm{m}^{2}\right)$,

$q^{\prime \prime}{ }_{k o}=$ fluks konduksi $(\mathrm{q} / \mathrm{A})$ menuju dinding $\left(\mathrm{W} / \mathrm{m}^{2}\right)$.

\subsection{Proses Konduksi Panas Pada Dinding}

Perpindahan panas konduksi pada dinding atau selubung bangunan menghubungkan kesetimbangan panas sisi luar dan sisi dalam sehingga perpindahan panas konduksi mengatur beban pendinginan ruangan terhadap waktu. Perpindahan panas konduksi pada selubung bangunan dalam perangkat lunak simulasi energi bangunan menggunakan persamaan yang disebut dengan fungsi transfer konduksi (FTK) atau conduction transfer function (CTF).

FTK pada lapisan dalam selubung bangunan menggunakan persamaan. 


$$
q^{\prime \prime}{ }_{k i}(t)=-Z_{o} T_{i, t}-\sum_{j=1}^{n z} Z_{j} T_{i, t-j \delta}+Y_{o} T_{o, t}+\sum_{j=1}^{n z} Y_{j} T_{o, t-j \delta}+\sum_{j=1}^{n q} \emptyset_{j} q^{\prime \prime}{ }_{k i, t-j \delta}
$$

Sedangkan FTK untuk lapisan luar selubung bangunan menggunakan persamaan.

$$
q^{\prime \prime}{ }_{k o}(t)=-Y_{o} T_{i, t}-\sum_{j=1}^{n z} Y_{j} T_{i, t-j \delta}+X_{o} T_{o, t}+\sum_{j=1}^{n z} X_{j} T_{o, t-j \delta}+\sum_{j=1}^{n q} \emptyset_{j} q^{\prime \prime}{ }_{k o, t-j \delta}
$$

Dimana :

$\mathrm{X}_{\mathrm{j}} \quad=$ FTK sisi luar, $\mathrm{j}=0,1, \ldots \mathrm{nz}$,

$\mathrm{Y}_{\mathrm{j}} \quad=$ FTK di dalam selubung bangunan, $\mathrm{j}=0,1, \ldots \mathrm{nz}$,

$\mathrm{Z}_{\mathrm{j}} \quad=$ FTK sisi dalam, $\mathrm{j}=0,1, \ldots \mathrm{nz}$,

$\Phi_{\mathrm{j}} \quad=$ FTK fluks, $\mathrm{j}=1,2, \ldots$ nq,

$\delta \quad=$ langkah waktu (time step),

$\mathrm{T}_{\mathrm{i}} \quad=$ temperatur sisi dalam $\left({ }^{\circ} \mathrm{C}\right)$,

$\mathrm{T}_{\mathrm{o}} \quad=$ temperatur sisi luar $\left({ }^{\circ} \mathrm{C}\right)$,

$\mathrm{q}^{\prime \prime}{ }_{\mathrm{ki}} \quad=$ fluks perpindahan panas konduksi pada sisi dalam $\left(\mathrm{W} / \mathrm{m}^{2}\right)$,

$\mathrm{q}^{\prime \prime}$ ko = fluks perpindahan konduksi pada sisi luar $\left(\mathrm{W} / \mathrm{m}^{2}\right)$.

2.6 Kesetimbangan Panas Sisi Dalam

Kesetimbangan panas sisi dalam menggunakan persamaan ${ }^{[3]}$ :

$q{ }_{L W X}+q{ }_{s W}+q{ }_{L W S}+q{ }_{k i}+q{ }_{s o l}+q{ }_{c o n v}=0$

Dimana :

$q{ }_{L W X}=$ netto pertukaran fluks radiasi gelombang panjang antar permukaan selubung zona $\left(\mathrm{W} / \mathrm{m}^{2}\right)$,

$q{ }^{\prime}{ }_{S W} \quad=$ fluks radiasi gelombang pendek dari cahaya ke permukaan $\left(\mathrm{W} / \mathrm{m}^{2}\right)$,

$q{ }_{L W S} \quad=$ fluks radiasi gelombang panjang dari peralatan yang ada di dalam ruangan $\left(\mathrm{W} / \mathrm{m}^{2}\right)$,

$q{ }_{k i} \quad=$ fluks perpindahan panas konduksi melalui dinding $\left(\mathrm{W} / \mathrm{m}^{2}\right)$,

$q{ }^{\prime}$ sol $\quad=$ fluks transmisi radiasi matahari yang diserap pada permukaan $\left(\mathrm{W} / \mathrm{m}^{2}\right)$,

$q "$ conv $=$ fluks perpindahan panas konveksi menuju udara ruangan $\left(\mathrm{W} / \mathrm{m}^{2}\right)$

2.7 Kesetimbangan Panas Udara di Dalam Zona

Persamaan kesetimbangan panas di dalam zona ditunjukkan oleh persamaan ${ }^{[3]}$ :

$q^{\prime \prime}{ }_{c o n v}+q{ }_{C E}+q{ }_{I V}+q{ }^{\prime}{ }_{s y s}=0$

Dimana :

q" conv = laju panas konveksi dari permukaan (W),

q" $C E=$ komponen laju panas konveksi dari beban internal (W),

q" ${ }_{I V}=$ beban sensibel yang disebabkan oleh udara infiltrasi dan ventilasi (W),

q" ${ }_{\text {sys }}=$ perpindahan panas dari atau ke sistem tata udara $(\mathrm{W})$. 


\subsection{Beban Pendinginan Penghuni}

Beban pendinginan penghuni adalah beban pendinginan internal bangunan yang memiliki karakteristik tersendiri dibandingkan beban pendinginan internal yang lain. Beban pendinginan penghuni dipengaruhi oleh dua faktor yaitu, tingkat hunian (okupansi) dan aktivitas yang dilakukan oleh penghuni. Panas yang dihasilkan dari aktivitas metabolisme menyebabkan keberadaan manusia di dalam bangunan mempengaruhi konsumsi energi bangunan secara keseluruhan. Laju panas yang dihasilkan oleh aktivitas metabolisme bergantung pada kegiatan yang dilakukan.

\subsection{Beban Pendinginan Sistem Tata Cahaya}

Konsumsi energi sistem cahaya berubah menjadi energi panas dalam tiga bagian, yaitu radiasi gelombang pendek, radiasi gelombang panjang dan konveksi. Ketiga fraksi tersebut ada yang didistribusikan ke dalam ruangan (space fraction) dan ada pula yang didistribusikan ke dalam langit-langit sehingga berinteraksi dengan udara balik sistem tata udara (plenum/return air fraction). Pembagian fraksi panas yang dihasilkan oleh sistem tata cahaya dapat dihitung menggunakan persamaan berikut ${ }^{[4]}$.

$$
f_{\text {convected }}=1,0-\left(f_{r e t}+f_{l w}+f_{s w}\right)
$$

$$
\begin{aligned}
& \text { Dimana } \\
& f_{\text {convected }}=\text { fraksi panas yang didistribusikan secara konveksi } \\
& f_{\text {ret }}=\text { fraksi panas yang diserap oleh udara balik } \\
& f_{\text {lw }}=\text { fraksi radiasi gelombang panjang } \\
& f_{\mathrm{sw}}=\text { fraksi radiasi gelombang pendek }
\end{aligned}
$$

\subsection{Beban Pendinginan Peralatan Listrik}

Pembagian energi yang dikonsumsi oleh peralatan listrik dapat dihitung menggunakan persamaan berikut ${ }^{[4]}$.

$$
f_{\text {convected }}=1,0-\left(f_{l}+f_{r}+f_{w}\right)
$$

Dimana :

$f_{\text {convected }}=$ fraksi panas yang didistribusikan secara konveksi

$f_{1}=$ fraksi panas laten

$f_{\mathrm{r}}=$ fraksi panas radiasi

$f_{\mathrm{w}}=$ fraksi energi yang berubah menjadi kerja

\subsection{Sistem Tata Udara}

Tujuan sistem pengkondisian udara adalah mengontrol dan mempertahankan suhu, kelembaban, gerakan udara, kebersihan udara, tingkat suara, dan tekanan diferensial dalam ruang dalam batas-batas yang telah ditentukan untuk kenyamanan dan kesehatan penghuni ruang yang dikondisikan dalam beraktivitas yang produktif. Kenyamanan termal bagi penghuni didasari oleh dua hal, yaitu suhu dan kelembaban. Ada rentang nilai tertentu yang harus dipenuhi agar kenyamanan termal bagi penghuni dapat terpenuhi. Manusia akan merasakan kenyamanan secara termal jika suhu ruangan antara $20{ }^{\circ} \mathrm{C}-26{ }^{\circ} \mathrm{C}$, dengan kelembaban $45 \%$ $55 \%$ dan kecepatan udara $0,25 \mathrm{~m} / \mathrm{s}$. 
Ada beberapa jenis sistem pengkondisian udara, diantaranya adalah yang akan dilakukan simulasi menggunakan EnergyPlus pada penelitian ini, yaitu:

- Unitary Packaged System

Sistem pengkondisian udara ini merupakan suatu sistem yang telah di kemas sedemikain rupa baik unit tunggal maupun dua unit sistem terpisah (split system). Sebuah unit tunggal terdiri dari kipas, koil DX, kompresor, kondenser dan aksesoris lainnya, sedangkan untuk sistem split terdiri dari bagian di dalam ruangan (air handler unit) dan bagian di luar ruangan (condensing unit). Air handler unit terdiri dari fan, filter, dan koil DX dan untuk condensing unit terdiri dari kondenser dan kompresor ${ }^{[5]}$.

- Variabel Air Volume System.

Sistem VAV mendistribusikan jumlah udara yang bervariasi untuk temperatur yang konstan. Dengan adanya kontrol jumlah udara, tingkat kenyaman di dalam suatu zona dapat disesuaikan dengan jumlah beban yang ada pada zona tersebut ${ }^{[6]}$. Sehingga hal ini sangat dapat memberikan penghematan dalam hal sistem pendinginan udara.

\section{HASIL DAN PEMBAHASAN}

Pembuatan model bangunan menggunakan aplikasi SketchUp Make 2017 + Plug-In OpenStudio. Proses pemodelan geometri bangunan dibagi menjadi tiga langkah, yaitu pemodelan geometri selubung bangunan, pembagian zona bangunan dan pemodelan material penyusun selubung bangunan. Model bangunan ditunjukkan pada Gambar 3.1.

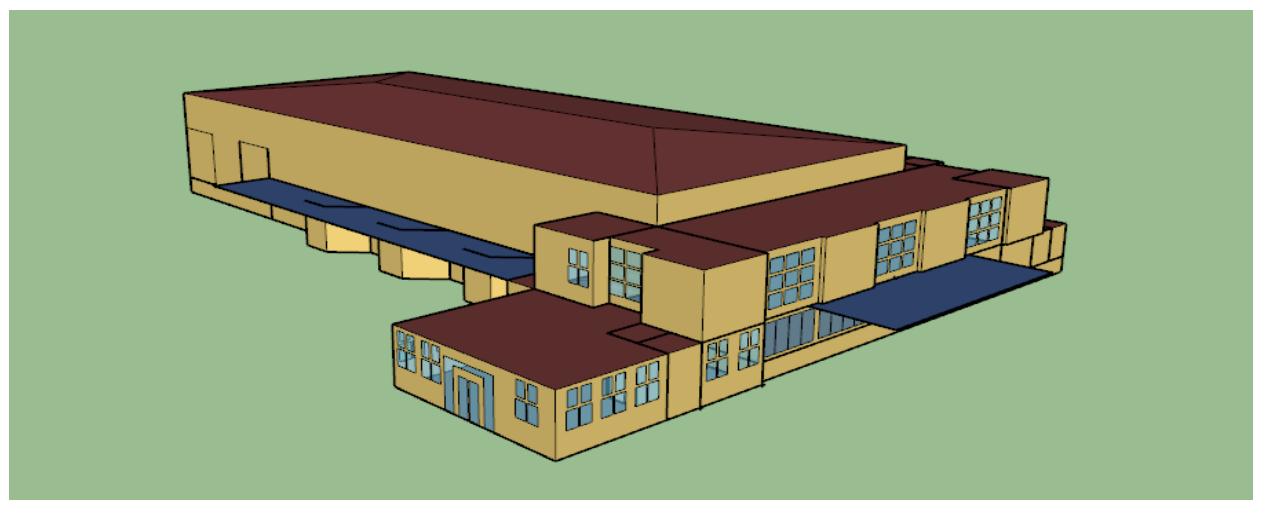

Gambar 3.1 Desain Model Gelanggang Mahasiswa USU

Data masukan yang diproses oleh EnergyPlus adalah model geometri dan konstruksi bangunan Gelanggang Mahasiswa USU, beban pendinginan penghuni, perangkat pencahayaan, Sistem HVAC (Pada Gelanggang Mahasiswa USU menggunakan Sistem Split atau Unitary System), peralatan listrik dan data cuaca dan lingkungan.

\subsection{Konsumsi Energi Bangunan}

Untuk konsumsi energi listrik pada ruang pusat Gelanggang Mahasiswa ditampilkan pada tabel 3.1 dan Gambar 3.2. Dari hasil simulasi, total konsumsi energi ruang pusat Gelanggang Mahasiswa adalah sebesar $7760.3 \mathrm{kWh} /$ bulan. Komponen yang beroperasi yaitu cooling, fans, interior lighting dan interior equipmen. Pemakaian energi listrik terbesar ialah mesin pendingin (AC) dengan pemakaian 78\% dari total keseluruhan konsumsi energi. 
Tabel 3.1 Hasil Simulasi Konsumsi Energi Listrik

\begin{tabular}{|l|l|}
\multicolumn{1}{|c|}{$\begin{array}{c}\text { End Use } \\
\text { Components }\end{array}$} & $\begin{array}{l}\text { Electricity } \\
{[\mathbf{k W h}]}\end{array}$ \\
\hline Cooling & 5459.55 \\
\hline Interior Lighting & 1107.67 \\
\hline $\begin{array}{l}\text { Interior } \\
\text { Equipment }\end{array}$ & 648 \\
\hline Fans & 545.07 \\
\hline Total End Uses & 7760.3 \\
\hline
\end{tabular}

\section{Konsumsi Energi [kWh]}

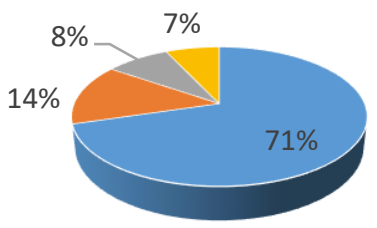

- Cooling - Interior Lighting - Interior Equipment - Fans

Gambar 3.2 Hasil Simulasi Konsumsi Energi Listrik

\subsection{Intensitas Konsumsi Energi (IKE) Bangunan}

Salah satu parameter yang dapat digunakan untuk menentukan kinerja energi bangunan (building energy performance) adalah nilai Intensitas Konsumsi Energi (IKE). IKE adalah konsumsi total energi bangunan selama periode waktu dibagi dengan luas lantai bangunan. Satuan yang digunakan untuk menyatakan IKE pada umumnya adalah $\mathrm{kWh} / \mathrm{m}^{2} /$ tahun atau $\mathrm{kWh} / \mathrm{m}^{2} /$ bulan.

Nilai IKE untuk bangunan ruang pusat gelanggang mahasiswa yang telah disimulasikan adalah $6.51 \mathrm{kWh} / \mathrm{m}^{2} /$ bulan. Penggunaan energi pada ruang pusat Gelanggang Mahasiswa sudah tergolong sangat efisien seperti terlihat pada Tabel 3.2.

Tabel 3.2 Standar IKE Departemen Pendidikan Nasional Republik Indonesia Tahun 2004

\begin{tabular}{clcc}
\hline No. & Kriteria & $\begin{array}{c}\text { Ruang ber-AC } \\
\left(\mathbf{k W h} / \mathbf{m}^{2} / \mathbf{b l n}\right)\end{array}$ & $\begin{array}{c}\text { Ruang tanpa AC } \\
\left(\mathbf{k W h} / \mathbf{m}^{2} / \mathbf{b l n}\right)\end{array}$ \\
\hline 1. & Sangat Efisien & $4.17 \mathrm{~s} / \mathrm{d} 7.92$ & $0.84 \mathrm{~s} / \mathrm{d} 1.67$ \\
2. & Efisien & $7.92 \mathrm{~s} / \mathrm{d} 12.08$ & $1.67 \mathrm{~s} / \mathrm{d} 2.50$ \\
3. & Cukup Efisien & $12.08 \mathrm{~s} / \mathrm{d} 14.58$ & - \\
4. & Agak Boros & $14.58 \mathrm{~s} / \mathrm{d} 19.17$ & - \\
5. & Boros & $19.17 \mathrm{~s} / \mathrm{d} 23.75$ & $2.50 \mathrm{~s} / \mathrm{d} 3.34$ \\
6. & Sangat Boros & $23.75 \mathrm{~s} / \mathrm{d} 37.75$ & $3.34 \mathrm{~s} / \mathrm{d} 4.17$ \\
\hline
\end{tabular}

\subsection{Skenario Peluang Hemat Energi (PHE)}

Meskipun sudah efisien, penghematan energi masih dapat dilakukan. Pemakaian konsumsi energi terbesar terdapat pada pengkondisian udara (AC). Skenario Peluang Hemat Energi (PHE) yang dapat dilakukan yaitu dengan mengganti sistem HVAC. Sistem HVAC yang diganti adalah dari Unitary System menjadi Variable Air Volume (VAV) System. Sistem VAV 
adalah sistem yang memberikan variasi volume udara yang konstan untuk memenuhi kondisi beban pendinginan ruangan yang berubah.

\subsection{Perbandingan Hasil Simulasi}

Dari hasil simulasi, total konsumsi energi listrik menggunakan sistem VAV (Variable Air Volume System) adalah sebesar $4573.57 \mathrm{kWh} /$ bulan, sedangkan untuk IKE menggunakan Sistem VAV adalah sebesar $3.84 \mathrm{kWh} / \mathrm{m}^{2} /$ bulan. Hasil konsumsi energi secara rinci ditampilkan pada Tabel 3.3 dan Gambar 3.3. Perbandingan konsumsi energi listrik dan IKE sebelum dan sesudah skenario Peluang Hemat Energi (PHE) terdapat pada Tabel 3.4 dan dapat disimpulkan bahwa dengan mengganti sistem HVAC dari Unitary System (AC Split) ke VAV System dapat menghemat sebesar $41 \%$ pemakaian energi listrik.

Tabel 3.3 Konsumsi Energi Listrik Sistem VAV

\begin{tabular}{|l|l|l|}
\hline End Use Component & $\begin{array}{l}\text { Electricity } \\
{[\mathbf{k W h}]}\end{array}$ & $\begin{array}{l}\text { Water } \\
{[\mathbf{m 3}]}\end{array}$ \\
\hline Cooling & 1778.23 & 0 \\
\hline Interior Lighting & 1107.67 & 0 \\
\hline Interior Equipment & 648 & 0 \\
\hline Fans & 311.31 & 0 \\
\hline Pumps & 536.26 & 0 \\
\hline Heat Rejection & 192.09 & 33.36 \\
\hline Total End Uses & 4573.57 & 33.36 \\
\hline
\end{tabular}

Konsumsi Energi VAV System [kWh]

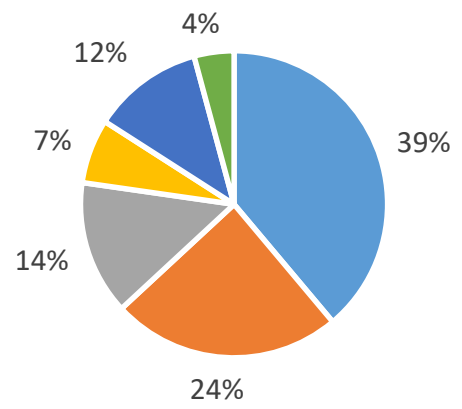

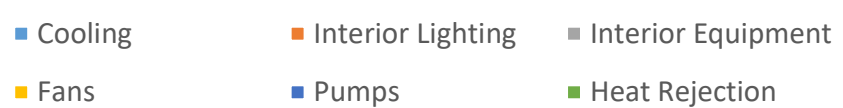

Gambar 3.3 Konsumsi Energi Listrik Sistem VAV

Tabel 3.4 Perbandingan Hasil Simulasi Sebelum dan Sesudah Penghematan

\begin{tabular}{|c|c|c|c|c|}
\hline & Sebelum & Sesudah & \multicolumn{2}{|c|}{ Penghematan } \\
\hline $\begin{array}{lcl}\text { Konsumsi } & \text { Energi } & \text { Listrik } \\
\text { Keseluruhan }[\mathrm{kWh} / \text { Bulan] } & \end{array}$ & 7760.3 & 4573.57 & 3186.73 & $41 \%$ \\
\hline IKE [kWh/m²/Bulan] & 6.51 & 3.84 & 2.67 & \\
\hline
\end{tabular}




\section{KESIMPULAN DAN SARAN}

\subsection{Kesimpulan}

Berdasarkan penelitian dan simulasi yang telah dilakukan dan dilaporkan pada bab-bab sebelumnya, maka kesimpulan yang didapat dari hasil penelitian ini adalah:

1. Konsumsi energi listrik dari ruang pusat Gelanggang Mahasiswa USU adalah sebesar $7760.3 \mathrm{kWh} / \mathrm{bulan}$.

2. Nilai Intensitas Konsumsi Energi (IKE) berdasarkan simulasi adalah sebesar 6.51 $\mathrm{kWh} / \mathrm{m}^{2} /$ bulan. Pemakaian Energi pada ruang pusat Gelanggang Mahasiswa USU sudah dikategorikan efisien.

3. Skenario konservasi energi yang dapat dilakukan untuk mendapatkan Peluang Hemat Energi (PHE) adalah dengan mengganti sistem HVAC dari Unitary System (AC Split) ke Variable Air Volume (VAV) System

4. Hasil penerapan skenario terhadap konsumsi energi listrik dengan simulasi didapatkan penghematan sebesar $41 \%$ dengan nilai IKE sebesar 3.84 $\mathrm{kWh} / \mathrm{m}^{2} /$ bulan.

\subsection{Saran}

Adapun saran untuk penelitian selanjutnya adalah:

1. Untuk penelitian selanjutnya, disarankan menggunakan EnergyPlus untuk audit energi dan simulasi bangunan di Universitas Sumatera Utara

2. Untuk mendapatkan hasil simulasi yang lebih baik disarankan untuk mendapatkan data material bangunan yang sebenarnya.

\section{REFERENSI}

[1] Green Building Council Indonesia. 2016. Sekilas Tentang Green Building.

[2] Badan Standardisasi Nasional. 2000. Prosedur Audit Energi pada Bangunan Gedung. SNI 03-6196-2000. Jakarta.

[3] ASHRAE. 2009. ASHRAE Handbook - Fundamentals (SI). Atlanta: American Society of Heating, Refrigerating and Air Conditioning Engineers, Inc.

[4] EnergyPlus Input-Output Reference. Dokumen teknis, AUniversity of Illinois, Urbana, Illinois, dan Ernest Orlando Lawrence Berkeley National Laboratory, Berkeley, California, Amerika Serikat, 2018.

[5] Wang, Shan K. 2001. Handbook of air conditioning and refrigeration, McGraw-Hill, USA.

[6] Wang, S.K. and Lavan, Z. 1999. Air-Conditioning and Refrigeration Mechanical Engineering Handbook, Boca Raton: CRC Press LLC. 